\title{
PSEUDACTEON OBTUSUS (DIPTERA: PHORIDAE) ATTACKING SOLENOPSIS INVICTA (HYMENOPTERA: FORMICIDAE) IN BRAZIL*
}

\author{
By David F. Williams and William A. Banks \\ USDA-ARS, \\ Insects Affecting Man and Animals Research Laboratory, \\ P.O. Box 14565, \\ Gainesville, Florida 32604, U.S.A.
}

Although parasitism of ants (Hymenoptera: Formicidae) by phorid flies (Diptera: Phoridae) has been reported by a number of investigators, their behavior is still poorly understood (Pergande, 1901; Wasmann, 1918; Borgmeier, 1925, 1931, 1963, 1969; Donisthorpe, 1927; Steyskal, 1944). Recently Williams et al. (1973), Williams and Whitcomb (1974) and Williams (1980) reported on two genera of phorids, Pseudacteon and Apodicrania, that attack fire ants in South America. They noted that Apodicrania larvae were endoparasites of fire ant larvae (Solenopsis invicta) while sixteen species of the genus Pseudacteon seem to parasitize workers of the Solenopsis saevissima complex. Although attacks by Pseudacteon on fire ants have been observed, evidence of actual parasitism (i.e. oviposition by the parasite) is lacking. Here, we report field observations of Pseudacteon attack on foraging $S$. invicta workers and document parasite oviposition on a host ant. Our observations indicate that the parasite preferentially attacks major workers of the host species. Possible reasons for this caste-bias are discussed.

Data were collected on April 18 (16:00-16:30), April 19 (11:00-15:30) and on April 24 (15:00-17:00), 1985 in Caceres, Mato Grosso, Brazil during studies of ant species competing for baits. At this time the phorid flies, Pseudacteon obtusus Borgmeier were observed hovering over workers of the fire ant Solenopsis invicta Buren as they fed at bait stations or moved along the foraging trails. Between one and four P. obtusus were observed during any one observation period. Only a few attempts $(n=3)$ were made by phorids to attack minor workers, and in these cases two of the minor workers escaped by crawling under debris, leaves or grass, while the

*Manuscript received by the editor October 8, 1986. 
third escaped by dispersing venom in the air by raising and vibrating its gaster (i.e., "gaster-flagging", Obin and Vander Meer, 1985). The attacking phorid would then fly in search of another potential host worker, and the minor worker would resume foraging. In contrast, no major workers displayed any defensive behavior such as gasterflagging, mandible gaping or lunging, although all of them tried to escape from attacking phorids. The major workers appeared "confused" by hovering phorids, moving off the foraging trail or away from the bait station into an open area (usually away from other workers). This action apparently benefited the parasite because the phorids closely pursued and attempted to oviposit only on major workers during this study ( $\mathrm{n}=10$ attempts), even though minor workers clearly outnumbered major workers at the bait station and along the foraging trails.

In one particular case, we observed a major worker of $S$. invicta under continuous attack by a lone phorid. We collected both host and parasite, placed them in a $20 \mathrm{ml}$ vial. Once in the vial, the phorid attempted repeatedly to land on the agitated worker which was running back and forth in the vial trying to elude the fly. After approximately $5 \mathrm{~min}$, the phorid landed successfully on the posterior end of the hosts' head capsule, deposited one oval egg, and then began searching for an exit from the vial, paying no attention to the ant. The ant, however, attempted to remove the egg with its antennae and forelegs. However, the placement of the egg at the base of the head capsule near its junction with the thorax made it impossible for the ant to do so. After several minutes of persistent attempts to dislodge the egg, the parasitized ant ceased grooming activities. We do not know whether or not the egg would have been removed by nestmates had the worker returned to its nest. Replicates $(n=5)$ of the above procedure were conducted using newly-mated female sexuals and other $P$. obtusus. These $P$. obtusus displayed no visible attack or oviposition behaviors while enclosed in a vial with individual $S$. invicta queens.

During this study, five other species of ants were observed foraging for baits in the study area. These included Mycocepurus sp., Conomyrma sp. A, Conomyrma sp. B, Paratrechina longicornis, and Acromyrmex sp.. However, only the Solenopsis workers were attacked by $P$. obtusus. 


\section{Discussion}

These observations represent the first, direct evidence that $P$. obtusus is parasitic; although other investigators have assumed this to be the case (Williams, 1980). Our observations also document $P$. obtusus attacks upon naturally occurring $S$. invicta workers at a distance from the fire ant nest. Previous studies (for example, Williams et al., 1973; Williams, 1980) have reported on attacks by phorids only on experimentally-disturbed fire ant mounds. Recently, however, Wojcik et al. (1986) discovered a single puparium of an unidentified phorid in a female alate.

Feener (1981) noted that phorids of the genus Apocephalus attack major workers of the ant Pheidole dentata and "stampede" the ant, thus overcoming its defensive behavior. P. obtusus appeared in our study to promote a similar response from its host. Parasitism of $P$. dentata also affected the competitive balance between it and $S$. texana (Feener, 1981).

Foraging $S$. invicta major workers appear more susceptible to successful attack by the phorid fly $P$. obtusus than workers of other size castes. This may be the result of larger ants presenting proximate, visual and/or chemical stimuli of greater magnitude than smaller ants. However, the fact that phorid females did not attack available sexuals which are as large or larger than majors suggests that other factors are involved. The preference for workers only is not unique to $P$. obtusus. Wasmann (1918) reported $P$. formicarum attacking only workers of Lasius spp. while ignoring winged males and females.

Defensive ability may be another factor. S. invicta major workers are less aggressive than minor and media workers (Wilson, 1978) and Vander Meer (unpublished data) has determined that the venom sacs of major workers contain significantly less venom alkaloids per mg ant than the venom sacs of other worker castes. Observations presented here suggest that such behavioral and physiological differences may render major workers particularly susceptible to parasitization by $P$. obtusus. However, factors other than ant aggressiveness and deterrent capability may also contribute to caste-bias in host selection by $P$. obtusus. Perhaps most significant in this regard is the site of parasite oviposition. Compared to minor or media workers, major workers offer a larger area at the 
base of the head capsule for securing an egg. An additional factor promoting the caste-bias in host selection observed in this study may be that major workers provide more nutrition for developing parasite larvae than non-major workers. This would be especially the case if $P$. obtusus larvae develop only in the head, a pattern observed in other species of ant-specific phorids (Pergande, 1901).

Finally, major workers may represent a more reliable resource. They are the longest-lived of the worker castes (Porter and Tschinkel, 1985), and their relatively reduced aggressiveness renders them least likely of all workers to incur injury or death from fighting. Therefore we suggest that the probability of an individual host surviving the requisite period of parasite development in that host is, on average, greater for major workers than for other workers. If so, selection would favor phorids that parasitize major workers.

\section{ACKNOWLEDGEMENT}

We wish to thank M. S. Obin for his excellent suggestions and comments on the manuscript. We also thank F. C. Thompson, D. R. Smith, and J. C. Trager for the identifications of the phorids and ant specimens. We are grateful for the assistance received from Antonio Pereira, Jorge Rodrigues and EMBRAPA in Brazil. Finally, we appreciate the opportunity afforded us by the U.S. and Brazilian governments to visit and study in Brazil.

\section{Literature Cited}

Borgmeier, T. 1925. Novos subsidios para o conhecimento da familia Phoridae (Dipt.) Arq. Mus. Nac. (Rio de Janeiro). 25: 85-273.

BorgmeIER, T. 1931. Sobre alguns phorideous que parasitam a sauva e outras formigas cortadeiras (Diptera, Phoridae). Archivos do Instituto Biologico. 4: 209-28.

Borgmeier, T. 1963. Revision of the North American phorid flies. Part 1. The Phorinae, Aenigmatiinae and Metopiniae, except Megaselia (Diptera, Phoridae). Studia Entomologica (Petropolis). 6: 1-256.

Borgmeier, T. 1969. New or little-known phorid flies, mainly of the Neotropical region (Diptera: Phoridae). Studia Ent. (Petropolis). 12: 33-132.

DonisthorPE, H. J. K. 1927. The guests of British ants, their habits and life histories. George Routledge \& Sons. London. 244 p.

Feener, D. H. 1981. Competition between ant species: outcome controlled by parasitic flies. Science 214: 815-817.

KistNeR, D. H. 1982. The social insects bestiary, p. 1-244. In H. R. Hermann (ed.), Social Insects. Academic Press, NY. Vol. 3, 459 p. 
Obin, M. S. and R. K. Vander Meer. 1985. Gaster flagging by the fire ants (Solenopsis spp.): functional significance of venom dispersal behavior. J. Chem. Ecol. 11: 1757-1768.

Pergande, T. 1901. The ant-decapitating fly. Proc. Ent. Soc. Wash. 4: 497-501.

Porter, S. D. AND W. R. TSCHINkel. 1985. Fire ant polymorphism: the ergonomics of brood production. Behav. Ecol. Sociobiol. 16: 323-336.

Steyskal, G. 1944. A new ant-attacking fly of the genus Pseudacteon, with a key to the females of the North American species (Diptera: Phoridae). Occasional Papers of the Museum of Zoology. Univ. Mich. No. 489: 1-4.

Wasmann, E. 1918. Zur Lebensweise und Fortpflanzung von Pseudacteon formicarum Verr. Biol. Zentralbl. 38: 317-329.

Williams, R. N., J. R. Panaia, D. Gallo, and W. H. Whitcomb. 1973. Fire ants attacked by phorid flies. Florida Ent. 56: 259-262.

Williams, R. N. AND W. H. Whitcomb. 1974. Parasites of fire ants in South America. Proc. Tall Timbers Conf. Ecol. Anim. Control Habitat Manage. 5: 49-59.

Williams, R. N. 1980. Insect natural enemies of fire ants in South America with several new records. Proc. Tall Timbers Conf. Ecol. Anim. Control Habitat Manage. 7: 123-134.

WILSON E. O. 1978. Division of labor in fire ants based on physical castes (Hymenoptera: Formicidae: Solenopsis). J. Kans. Entomol. Soc. 51: 615-636.

Wojcik, D. P., D. P. Jouvenaz, AND C. S. Lofgren. 1987. First report of a parasitic fly (Diptera: Phoridae) from a red imported fire ant (Solenopsis invicta) alate female (Hymenoptera: Formicidae) Florida Entomol. 70: 181-182. 

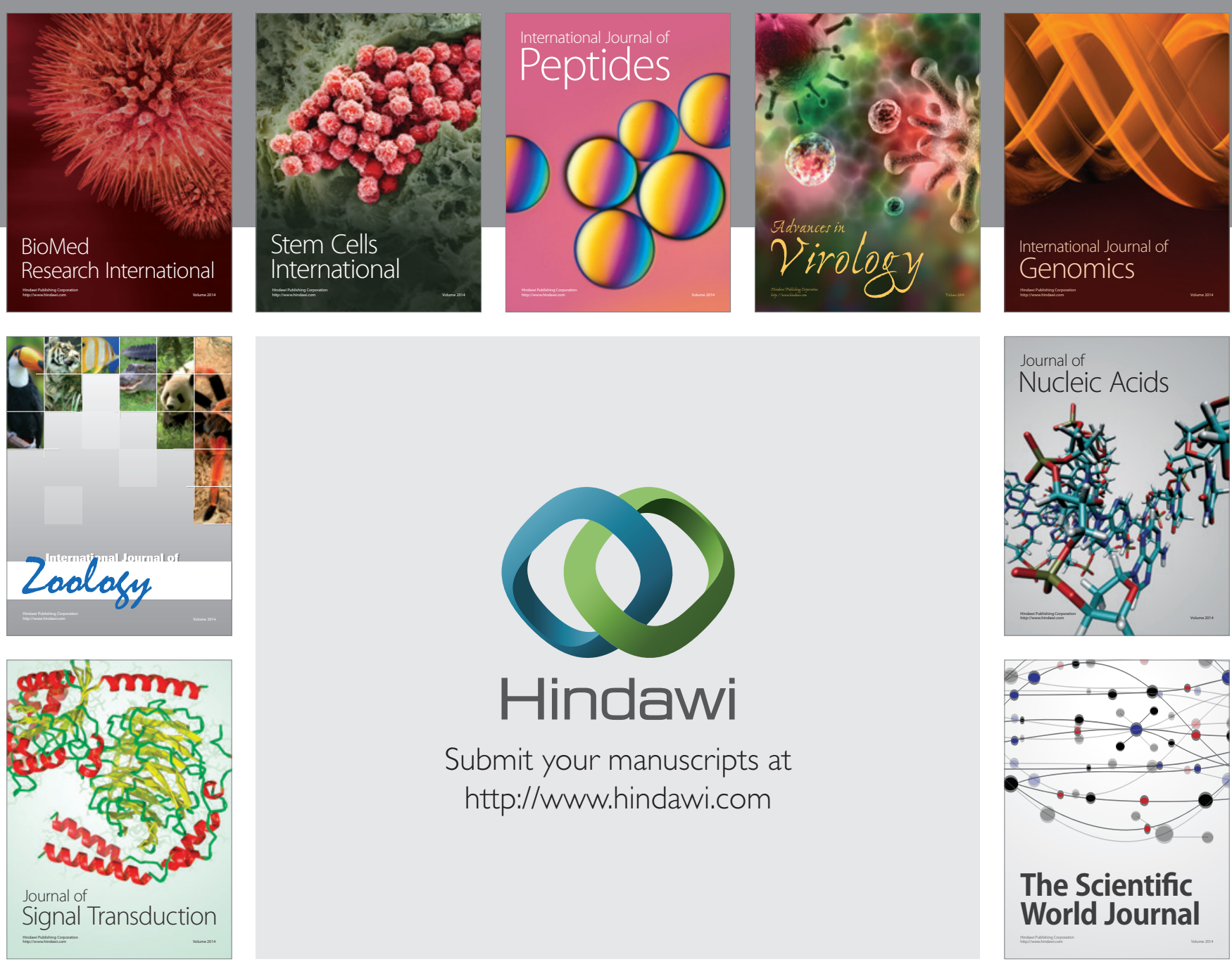

Submit your manuscripts at

http://www.hindawi.com
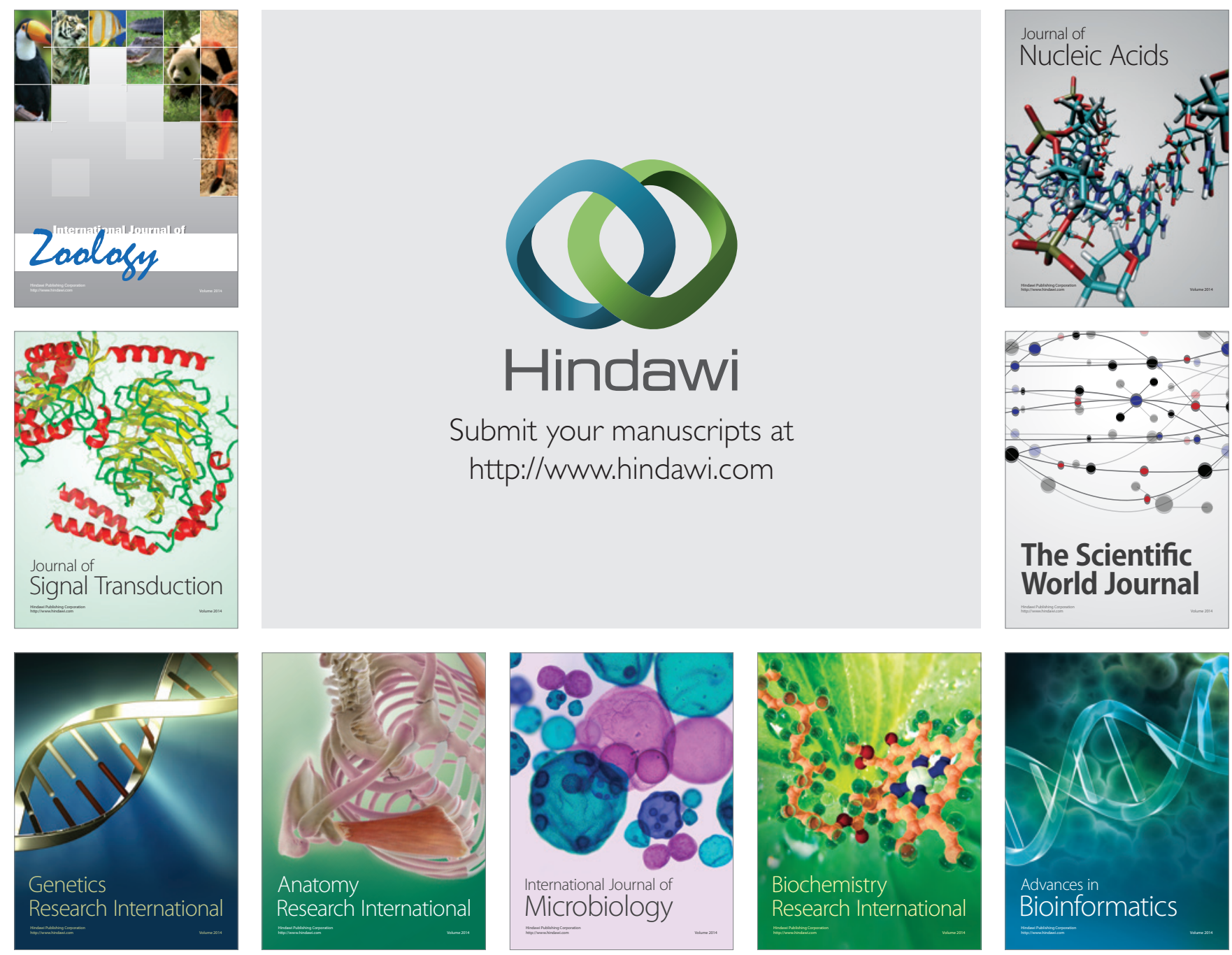

The Scientific World Journal
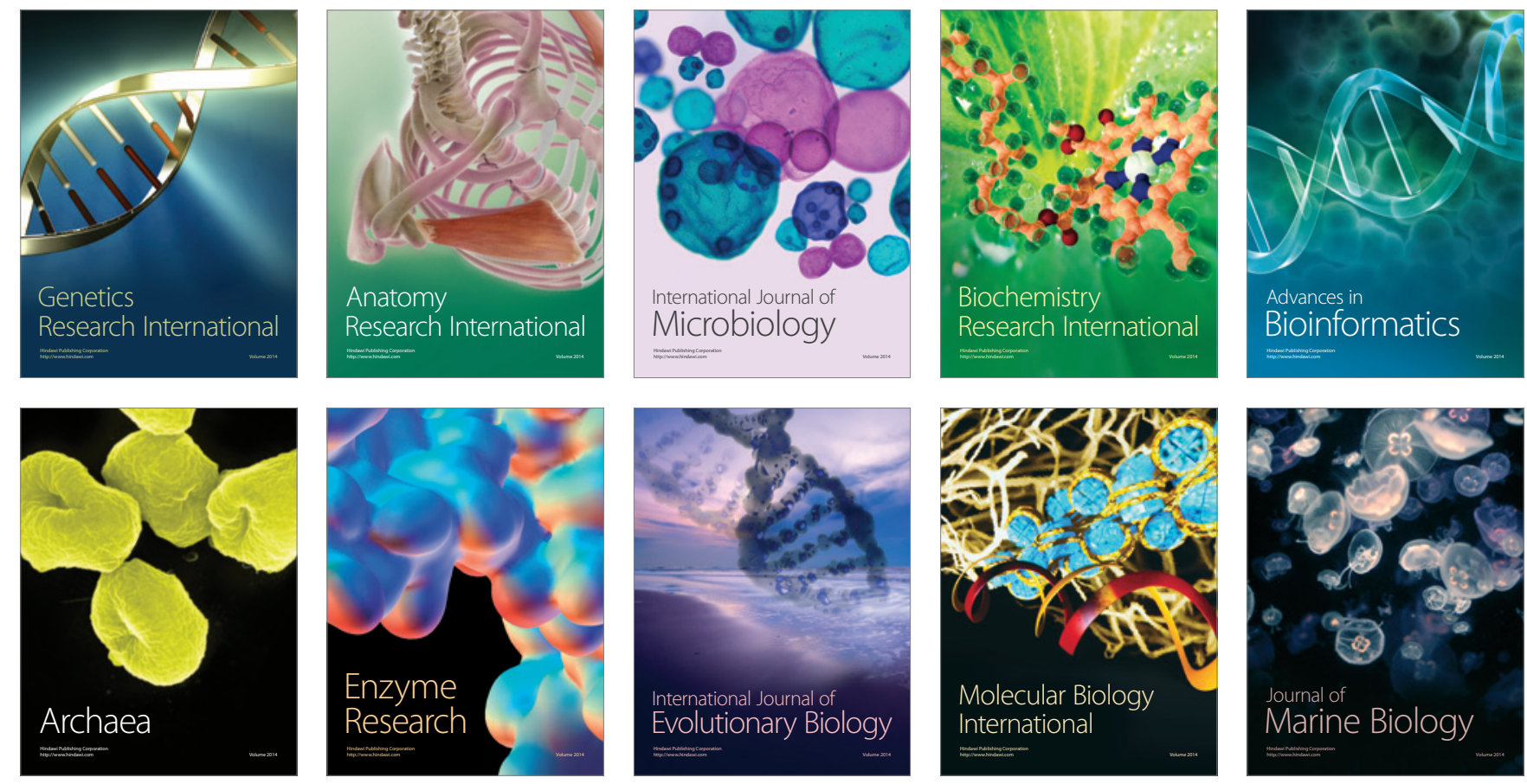